\title{
LA MÚSICA DE LA COSTA ATLÁNTICA COLOMBIANA \\ Transculturalidad e identidades en México y Latinoamérica
}

\author{
Darío Blanco Arboleda \\ Estudiante DE DOCTORADO EN CIENCIAS SOCIALES, \\ El Colegio de México \\ dblanco@comex.mx
}

\begin{abstract}
Resumen
[ STE TRABAJO TRATA LA MANERA EN QUE SE DA LA TRANSNACIONALIZACIÓN DEL VALLE[ nato y la cumbia entre Colombia y México, enfatizando cómo esta música ha servido a manera de herramienta en la construcción de procesos identificatorios; primero, por parte de un reducido grupo de campesinos en la costa atlántica; luego, en la construcción del departamento del Cesar, para terminar siendo la música colombiana; en contraste con este mismo fenómeno en México, particularmente en la ciudad de Monterrey-Nuevo León.

PALABRAS CLAVE: música colombiana, vallenato, cumbia, procesos identitarios, Colombia, México.
\end{abstract}

\begin{abstract}
THIS PAPER ADDRESSES THE TRANSNATIONALIZATION OF VALLENATO AND CUMBIA music between Mexico and Colombia, highlighting how it has served as tool for the construction of identity. It was first used as such by a small number of peasants living on Colombia's Atlantic coast, then as part of the construction of the Departamento del Cesar, and in the end has become identified as Colombian Music. This process is compared to the same phenomenon ocurring in Mexico, specifically the city of Monterrey in Nuevo León.

Key wORDs: Colombian music, vallenato, cumbia, identity, Colombia, México.
\end{abstract}




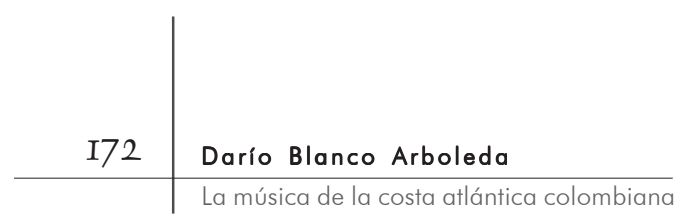

Aquí nos tienes de nuevo, humildemente en tu bonito festival, con la firme idea de ganar el primer puesto para que en tierra azteca tengan su cacique Upar. Con la firme idea de ganar el primer puesto para que en tierra azteca tengan su cacique Upar. A santo Ecce Homo siempre le vivo pidiendo me dé su licencia para mi meta lograr. Y si yo lo logro te juro Guadalupana que volviendo a mi tierra yo te lo voy a brindar. Y si yo lo logro te juro Guadalupana que volviendo a mi tierra yo te lo voy a brindar. iAyyi yo no soy, yo no soy del Magdalena, de La Guajira ni tampoco del Cesar.Yo soy de una tierra donde la influencia extranjera ihombre! poquito a poco con el folclor fue a acabar por eso le digo a toditos los vallenatos que si quieren su tierra cuiden su festival.

López, 2002.

\section{LA MÚSICA DE ACORdeÓN EN COLOMBIA}

$\int$ ON HARTO CONOCIDAS LAS ACCIONES DE VIOLENCIA PERPETRADAS A diario por las diferentes facciones que se enfrentan en el con$\checkmark$ flicto armado colombiano. En mi opinión, este conflicto, que desde hace varias décadas desangra al país, ha llegado hasta semejante punto debido, entre otros muchos factores, a la incapacidad de los habitantes de verse como una unidad y trazar propósitos comunes. Hasta la fecha, Colombia es más una conformación de diversas regiones que una unidad homogénea; está integrada por diversas zonas socioculturales que no han encontrado un punto de

I. Canción vallenata compuesta por un conjunto regio-colombiano para participar en el festival de la leyenda vallenata realizado en la ciudad de Valledupar (departamento de Cesar, Colombia). Es un claro ejemplo del sincretismo vivido por medio de este género musical. Este festival es el más importante de música vallenata, y en los últimos años ha contado con la participado de intérpretes mexicanos. El cacique Upar era el líder indígena de la región, de donde se toma el nombre para el Valle de Upar. Ecce Homo, el santo patrón de la ciudad, cuenta con gran devoción debido a sus milagros. unión; no se ha podido concebir como país, y desde la independencia de España se libran sangrientas guerras civiles, sin encontrar una tregua.

Los dirigentes políticos, los líderes y los medios de comunicación masiva que han entendido esta carencia han buscado un elemento de cohesión cultural. En la actualidad, esta búsqueda de unión se realiza por intermedio de diversos instrumentos, entre los que se destacan el deporte, la música, las telenovelas y los reinados de belleza. De esta manera, por los medios de comunicación masiva se intenta unificar al país utilizando 


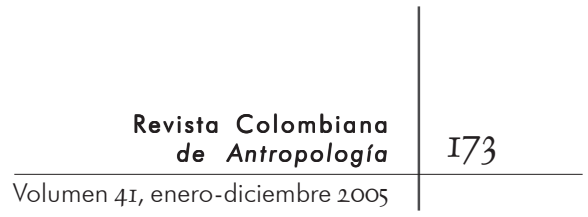

estos espectáculos como herramientas. En el caso que nos ocupa, el vallenato se comercializa como la música colombiana, se escucha a lo largo y ancho del país e, incluso, la diplomacia lo usa como el sonido de Colombia para el mundo. Se busca, desesperadamente, un elemento de unión para los connacionales, que les permita entenderse como semejantes y no como antagonistas. La manipulación del poder simbólico que posee esta música se encamina hacia esa dirección.

Este conflicto en su generalidad no es exclusivo de Colombia; así, por ejemplo, Araújo (2000: II5) trabaja esta misma problemática, pero en el caso de Brasil, preguntándose cómo se ha utilizado la música en la representación de identidades sociales. Brasil es una nación con una gran diversidad y grandes iniquidades, con diferentes modelos culturales y jerarquías sociales, por lo cual es necesaria la búsqueda continua de unidad nacional; dentro de esta, la música negra y el baile han desempeñado un papel prominente, al igual que en Colombia.

Durante 2002, el Ministerio de Cultura hizo la gran encuesta nacional de cultura, con un universo de mil personas de veintiocho municipios del país. La sorpresa fue que existe una hegemonía cultural de la costa atlántica, aun cuando, históricamente, la zona central andina ha ocupado ese lugar. Las actividades artísticas o culturales consideradas más importantes fueron, en orden: el reinado nacional de la belleza, el carnaval de Barranquilla y el festival de la leyenda vallenata. Los personajes más admirados son: Gabriel García Márquez, Shakira y Carlos Vives. Y la manifestación cultural que hace sentir más patriotas a los colombianos, que sirve de mejor manera como aglutinante nacional, resultó ser el vallenato, con un tercer lugar para el bambuco del interior andino. Otros datos destacados: trece de los veintinueve personajes más admirados son músicos; escuchar música es la principal actividad cultural pasiva del país; la dan$z a$ la primera actividad que se viene a la cabeza cuando se piensa en la palabra cultura; y la música es la principal herencia cultural que se desea dejar a los hijos. La radio es considerada el principal motor de la cultura, por encima de la prensa o la televisión (Bejarano, 2002). A partir de esta muestra se dice que los colombianos se aferran a la cultura como prueba de vida, como mecanismo de salvación, de convivencia, de entendimiento, y se piensa en ella como garantía de un futuro (El Tiempo, 2002). 


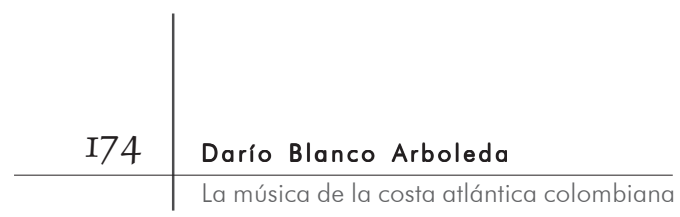

Esta encuesta confirma la idea expuesta antes, de que por medio de la música se busca, se intenta, unificar el país y lograr que la población se sienta parte del "artefacto cultural de la comunidad política colombiana imaginada" (parafraseando a Anderson, I983 [I99I]: 2I); ya que, precisamente, esta idea de comunidad imaginada es la que no está operando dentro del concepto de colombianidad. Los estudios sobre este fenómeno deben señalar la importancia del papel de la música dentro del imaginario de cohesión nacional y la preeminencia que debe tener al pensarse en políticas que busquen detener la fragmentación social y encontrar la solución pacífica de las diferencias.

El vallenato en su expansión nacionalizadora ha sido sometido a un proceso de blanqueamiento, ya que esta música, con claras influencias afro, debe mimetizar las mismas con el fin de ser más aceptada. Esta es una música que en su corta historia ha sido utilizada por diversos grupos sociales como herramienta identitaria, en diversas geografías y temporalidades. Ha debido transformarse, cambiar parte de sus elementos constitutivos en el proceso de eugenesia cultural al que se ve sometida, con el fin de ser aceptada en nuevos nichos sociales y desarrollarse en los mismos, después de ser resignificada de acuerdo con los parámetros de la cultura receptora.

La música vallenata es un producto masificado por las disqueras del país y en la actualidad tiene una gran presencia en los medios de comunicación masiva. En ella se conjugan la música con la poesía popular, con una fuerte influencia de la oralidad, de la que recibe su fuerza; posee una amplia aceptación popular en toda la costa atlántica rural y pueblerina, y en los últimos años su aceptación se ha ampliado, superando las fronteras de la costa atlántica e, inclusive, los límites nacionales.

El vallenato actual es un producto comercial que se ve regulado por las leyes del mercado y queda expuesto al juicio valorativo de sus consumidores. Debido a esto cambia sus parámetros constantemente, de acuerdo, en primera instancia, con las exigencias comerciales impuestas por las disqueras y estaciones de radio.

En el interior del país la música de acordeón se rechazó durante mucho tiempo, por considerar que procedía de negros, pertenecientes a una clase social baja. Hoy en día, esa música, que no tenía la posibilidad de emerger de su grupo productor incluso en la costa atlántica, es la que el mercado discográfico, 


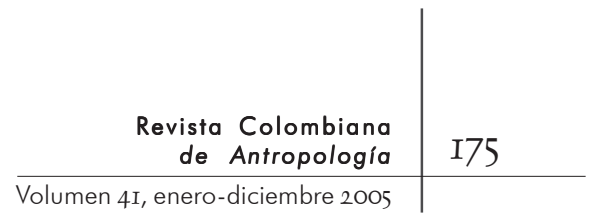

el imperio comercial, ha instituido como la música colombia$n a^{2}$. En este proceso se encuentran intereses políticos regionales y nacionales, y eso nos lleva a que, en los últimos años, el vallenato se haya extendido por todo el país y haya cruzado las fronteras, erigiéndose como la música colombiana más representativa.

La música de acordeón posee, desde sus inicios, múltiples variantes regionales y diversas historias en torno a sí misma. Esto es claro en los aires, ya que algunos varían según la zona de procedencia. En este artículo* me concentraré en el proceso de regionalización y de nacionalización, por medio del ejemplo de dos músicos pertenecientes a las elites y que sólo reflejan parte de la historia del género. Sin embargo, es necesario aclarar que aun cuando estos dos artistas muestran puntos clave de expansión dentro de la masa receptora, en especial de aceptación y consumo por parte de las clases sociales medias y altas, paralelamente otros músicos, de raigambre y estilo popular, fueron los encargados de expandir esta música por toda la geografía, llegando incluso a países fronterizos como Venezuela y Ecuador, y han sido escucha-

2. Mientras el vallenato ha funcionado internamente como herramienta de cohesión nacional, la cumbia ha cumplido la función de representarnos en el extranjero, a manera de embajadora cultural.

* Este artículo está formado, parcialmente, por material de mi tesis de licenciatura y de la de maestría. La primera, titulada "Creaciones, dinámicas y contradicciones del vallenato: construcción de regionalidad y nacionalidad a partir de la música popular colombiana", presentada en la Universidad de los Andes (Bogotá), 2000; la segunda: "La relación música e identidad. El movimiento regiocolombiano, sincretismo en México de la música de la costa atlántica colombiana", Universidad Autónoma Metropolitana-Iztapalapa (México, D. F.), 2003. dos masivamente sólo por las clases populares. Este proceso puede seguirse por medio de figuras como Alejo Durán, Alfredo Gutiérrez, el Binomio de Oro o Diomedes Díaz, entre otros.

\section{El vallenato de Rafael Escalona}

$\bigcap_{\mathrm{q}}$ AFAEL ESCALONA ES UN PERSONAJE MUY IMPORTANTE DENTRO DE LA historia de Colombia, y de esto da prueba Gabriel García Márquez cuando en honor a él dijo que: "Cien años de soledad no era más que un vallenato de 350 páginas”. Es uno de los compositores más prolíficos y el primero en cambiar los patrones estéticos de la música de acordeón para convertirla en vallenato; 


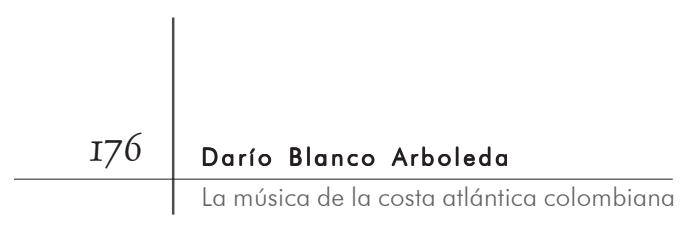

fue pieza fundamental en el proceso de su aceptación por parte de las clases altas de la costa atlántica y en sus primeras incursiones hacia el altiplano. Tomó una música de negros y clases bajas y logró introducirla en los salones de baile de toda la costa atlántica. Sólo a alguien como él, que provenía de una familia acomodada de Valledupar y que hacía parte de la elite, le fue posible la primera gran transformación de la música de acordeón, introduciéndole nuevas temáticas a las canciones, pero a grado tal que sus cultores y receptores no sintieran que se había pervertido su esencia misma ${ }^{3}$. Sin alejarse demasiado de la esencia de este género musical, Escalona logró componer canciones que no hablaban de la ardua labor campesina, como hasta entonces, sino que introdujo hábilmente en sus canciones a las grandes personalidades de la región. Estas historias interesaban sobre todo a las elites, porque eran sus protagonistas. También mantiene la costumbre de sus predecesores, los juglares, de no inventar nada en sus canciones: él cuenta lo que observa y lo hace con gracia y espontaneidad.

Además de no tocar el acordeón y de provenir de una familia acomodada, Escalona tiene una tercera característica que lo diferencia de los músicos de su generación: no canta, sólo compone para que otros canten. Como puede verse, es una figura diferente dentro de los parámetros de la música de acordeón tradicional. Transformó los cánones -abriendo el camino para los cambios radicales y la transformación de esta música en el vallenato, que surgiría años después- hasta llegar al vallenato que escuchamos en la actualidad. Él se hizo famoso nacionalmente de forma diferente que los demás músicos de acordeón,

3. Dentro de los parámetros de las expresiones de una manera que no va de la musicales existe consenso acerca de qué puede ser cambiado y hasta qué punto, sin que se traspase el límite del propio género musical y se pase a hablar de uno nuevo. Este consenso sólo puede ser establecido por el mismo campus, en el sentido de Bourdieu, compuesto por los productores, críticos y consumidores del género. mano de lo tradicional, ya que sus cantos se dieron a conocer primero en la voz de Guillermo Buitrago y luego con Bovea y sus vallenatos, pero no acompañados de acordeón, caja y guacharaca, la instrumentación tradicional, como era de esperarse, sino de guitarra y maracas, instrumentos menos estigmatizados (Restrepo, I99I: 75).

Escalona logró lo que era imposible hasta su aparición: la presencia regional, en todos los niveles sociales, de un fenómeno local de minorías relegadas y desdeñadas. Creó una nueva 


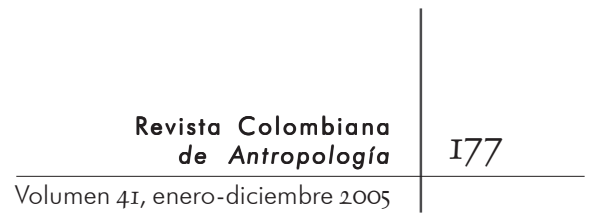

estética dentro de la música de acordeón, siendo parte primordial en la creación del vallenato ${ }^{4}$, entendido como la apropiación musical por parte de las elites de Valledupar de un folclor que pertenecía a toda la costa atlántica, y que actualmente consume la sociedad colombiana. Influye en un personaje tan importante para la cultura nacional como García Márquez, y su música es pieza fundamental dentro del segundo gran paso expansivo de este género.

Rafael Escalona representa el primer gran paso en la evolución de la música de acordeón; le brinda una nueva estética, la de un bachiller blanco perteneciente a una de las familias más prestantes de la región. Sin la aparición de una figura de sus condiciones, el vallenato como lo conocemos sería impensable.

\section{El vallenato de Carlos Vives}

ARLOS VIVES ES EL SEgUNDO GRAN INNOVADOR Y TRANSGRESOR DE LOS parámetros vallenatos establecidos. Es un artista que se tropieza con el éxito dentro de esta música, sin buscarlo ni quererlo. Es un actor y cantante muy lejano a la música popular colombiana, que trabajaba con el pop y el rock, hasta cuando fue llamado al papel protagónico de una serie televisiva sobre Escalona, en la que debía cantar las composiciones del maestro. Fue allí donde su carrera se unió definitivamente a este género musical.

Esto hecho le dio un giro radical a su vida y cambió, al mismo tiempo, la recepción en el mercado en relación con la música vallenata en el país. Vives se convirtió en vendedor de millones de discos, y por primera vez en la historia gente de toda la geografía colombiana y de todas las clases sociales se encontró escuchando y bailando vallenatos. Desde ese entonces se dedicó a cantar, en nuevas versiones, la música de acordeón tradicional, la de los grandes juglares, y a hacer canciones propias con grandes innovaciones pero buscando siempre que se en-

4. Más adelante, en el apartado sobre el festival de la leyenda vallenata, se explicará cómo el vallenato es una construcción de las elites de Valledupar, hecha a partir de la expropiación de la música de acordeón de toda la región, renombrándola y designándola con su propio gentilicio. musicales colombianas. 


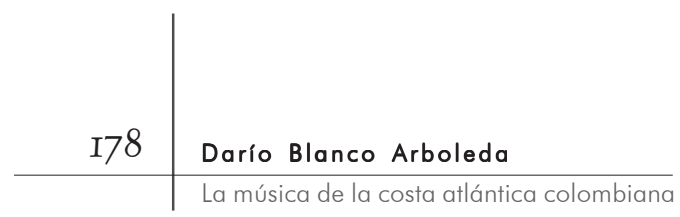

En el discurso de Vives y en las estrategias comerciales utilizadas para promocionar y vender sus producciones más recientes es posible observar como él va entrando a los parámetros del recientemente creado género de las músicas del mundo: world music. Allí, en un doble desplazamiento, se privilegia el regreso a lo primitivo, en una especie de labor de etnología de rescate, que busca preservar los últimos resquicios de lo exótico, suscitando una idealización del mundo periférico por medio de su música, para difundirlo luego de manera global. Es un rescate de lo regional, de minorías étnicas, para comercializarlo globalmente pero sobre todo en el mundo hegemónico: Europa, Japón y Estados Unidos. En este caso, lo exótico es representado por la provincia -término que se contrapone al de ciudad- que se refiere a las zonas rurales, con mayor atraso y donde los procesos modernizadores han sido implementados con mayor inconsistencia. El discurso de Vives y sus composiciones se remiten a esta provincia

5. Vives comenzó su carrera como cantante vallenato hacia I989-I990 con los discos Escalona I y Il; posteriormente, en I993, obtuvo su mayor éxito con Clásicos de la provincia, el disco más vendido en la historia de Colombia hasta ese momento. Luego viene La tierra del olvido, en el que comenzó a cantar sus propias canciones (I995), seguido por Tengo fe (I997), en el que hizo un nuevo desplazamiento hacia un concepto de música más adulta, sin mayor éxito. Esto lo obligó a regresar al anterior concepto, más relacionado con músicas del mundo, en El amor de mi tierra (1999) y Déjame entrar (200I).

6. "Las músicas del mundo crean su experiencia de autenticidad a través de medios simbólicos cuya diferenciación depende vitalmente de una construcción en la cual se borren las diferencias originales (...). En este escenario las fuerzas y los procesos de producción cultural se dispersan y se rompen sus referencias a cualquier tiempo y lugar, aun si precisamente son la tradición local y la autenticidad el principal producto que está vendiendo la industria del entretenimiento global" (Erlmann, citado por Ochoa, I998: I77). -en la costa atlántica colombiana-, término que denota también a su grupo de músicos. Más adelante él comenzó a referirse a esta provincia como la tierra del olvido ${ }^{5}$, frase que resume parte del proceso simbólico de las músicas del mundo .

Trajo consigo un fenómeno sólo comparable con el de Escalona, dadas las proporciones. Con Vives se dio el segundo gran paso en el proceso expansivo del vallenato. Él hizo con toda la nación lo que Escalona con la costa atlántica. Se dio, definitivamente, el salto de la aceptación regional a su nacionalización. Antes, otros cantantes y grupos -de performatividad claramente popular- habían logrado que el vallenato se escuchara en gran parte del territorio nacional, e incluso en otros países de la región, pero al igual que le ocurría a la música de acordeón antes de Escalona, que era música de clases bajas de la costa, el vallenato era la de las clases bajas del país: vigilantes, taxistas, empleadas del servicio 


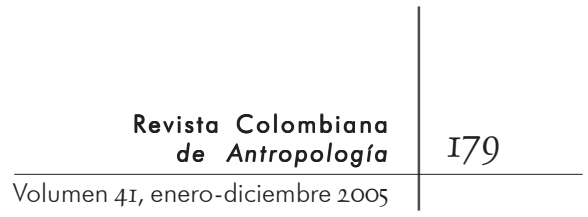

doméstico constituían el estereotipo de sus fanáticos. Vives tomó el vallenato y lo transformó de nuevo en dos vías contrapuestas: por un lado, lo modernizó, introduciéndole instrumentos y ritmos ligados al rock y al pop; por otro, lo tradicionalizó, incorporando de nuevo la gaita indígena, que había sido remplazada a principios del siglo veinte por el acordeón. Le dio una nueva imagen al vallenato y logró que todos los estratos sociales del país lo aceptaran. Por esto, debe resaltarse el paralelismo del fenómeno de Vives en lo nacional con el de Escalona en lo regional. No es ninguna coincidencia que el primero iniciara su vertiginoso ascenso, precisamente, con la música del maestro Escalona, ya que, como él, no pertenece al grupo de los músicos de acordeón tradicionales: es blanco, estrella de la televisión, elegido varias veces el hombre más atractivo de Colombia, ex esposo de una actriz muy importante, ex rockero que mantiene su imagen de pelo largo, camiseta y jeans. Utiliza esa imagen para lograr la aceptación de un grupo que jamás había sido atraído por el vallenato: los jóvenes de clase media y alta. Con la música del maestro Escalona, y catapultado por una serie televisiva, logró la aceptación dentro de las clases privilegiadas de todo el país en las diferentes generaciones.

Ochoa (I998: III, II2) plantea que el caso de Carlos Vives es un fenómeno clásico de cross-over, que es posible encontrar dentro de los géneros musicales que tienen elementos afroamericanos. Una de las características de este fenómeno es el tránsito de un género musical afroamericano a la aceptación masiva y el auge nacional, cuando es liderado por un músico blanco. Ejemplos del cross-over pueden encontrarse en la historia del blues y del rock. Según esta interpretación, Vives logró una des-africanización del género musical mediante su imagen, aceptable dentro de las clases medias y altas. El éxito no depende sólo de sus fusiones musicales, sino también de minimizar las raíces populares y africanas del género al mismo tiempo que resalta otras como las indígenas, más aceptadas y, por ende, con un perfil más comercial. De esta manera, blanquea el vallenato y lo hace aceptable a un país al que aún le cuesta aceptarse desde su pluralidad y sus tradiciones populares. Representa el segundo gran paso en la expansión de la música vallenata, y gracias a él se acepta totalmente tanto en lo vertical, atravesando de arriba abajo las clases sociales, como en lo horizontal, ampliando increíblemente la masa receptora. De igual manera, internacionaliza a gran escala el vallenato y pasa a 


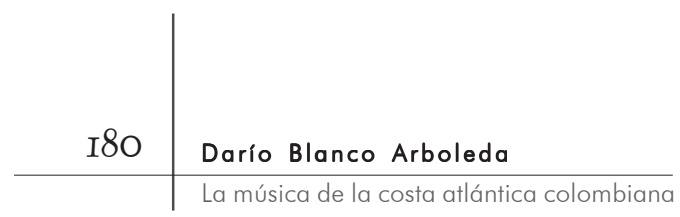

ser reconocido como la música colombiana en las más diversas regiones del planeta.

Después de su éxito Clásicos de la provincia comenzó a trabajar con la disquera major EMI, y se desplazó a Miami, ciudad centro de la industria del entretenimiento para Latinoamérica. Allí, Vives se asoció con el productor Emilio Esteffan, y como fruto de esto sus discos fueron nominados una y otra vez para los premios Grammy y lograron ser un éxito en ventas en toda Latinoamérica. De esta forma, él abrió la puerta del mercado internacional de la música a otros artistas jóvenes colombianos, como Shakira, Juanes o Andrés Cabas, que hoy en día han alcanzado también reconocimiento internacional.

\section{EL FESTIVAL DE LA LEYENDA VALLENATA}

L FESTIVAL DE LA LEYENDA VALLENATA FUE CREADO EN I968 POR UN grupo reducido de personalidades de Valledupar, que se apropiaron de un folclor de dimensiones regionales, instaurándolo y confiriéndole concepto de identidad a una región nueva necesitada de esta construcción identitaria. Separarse del antiguo Magdalena grande obligaba al nuevo departamento del Cesar y a su primer gobernador, Alfonso López Michelsen, a buscar un elemento que los uniera como departamento y los diferenciara de la antigua división política a la que estaban adscritos.

El festival vallenato ha evolucionado como evento. Sus primeras versiones eran libres y se trataba de ver a los participantes en acción. Poco a poco se fue organizando, con reglamentos y especificaciones técnicas. En la actualidad dista mucho de ser un evento folclórico: cada vez está más influido y determinado por las leyes de la industria discográfica y por el mercado.

Los organizadores del festival de la leyenda vallenata tienen una idea asociada históricamente al folclor: éste debe conservarse y guardarse sin permitir cambios de ninguna naturaleza, ya que debe deber ser protegido, como patrimonio regional-nacional, y resguardado de la influencia maligna del exterior, al igual que de la comercialización. En consecuencia, en su reglamento obligan a utilizar los instrumentos tradicionales, es decir, no permiten el uso de guacharacas metálicas y cajas con parche sintético, utilizadas mayoritariamente hoy en día por fines prácticos, 


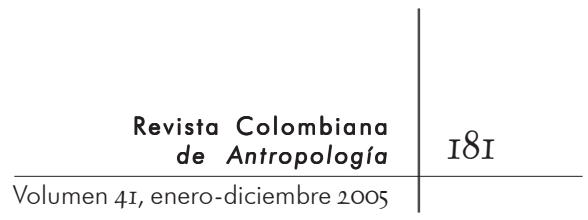

sonoros y económicos. Por otra parte, obligan a los participantes a tocar los cuatro aires vallenatos -merengue, paseo, puya y son-, impuestos por ellos como los tradicionales, usando su sitial de poder para reforzar el dominio que buscan sobre las demás expresiones del género que se dan fuera de Valledupar. Finalmente, lo que logran establecer es un evento de música de acordeón que busca emular la que se tocaba en su región a mediados del siglo veinte, y aun cuando presumen de ser la catapulta para el mantenimiento y el desarrollo del género, el vallenato que promueven desde el festival sólo existe durante éste, ya que la influencia de las nuevas generaciones, de la industria musical y la ampliación del género lo han transformado radicalmente, como era de esperarse, ya que paralelo al discurso folclorista encontramos un evento mass mediático, comercial en todo sentido, que refuerza las nuevas corrientes y tendencias vallenatas dictaminadas por la industria discográfica.

Es consistente con las tensiones sufridas por música local, de parte del mercado global, que un festival que promulga el mantenimiento del folclor lo más puro posible, reciba, sin embargo, participantes de otros países, como México. Durante los últimos cinco años, músicos de allí, regio-vallenatos, han participado en varias categorías, como mejor acordeonero y canción inédita.

Como folclor, la música de acordeón hacía parte de toda la región de la costa atlántica, pero con la necesidad que tenían las elites de Valledupar de crear un elemento cultural propio que la diferenciara de las demás regiones se fue dibujando una nueva historia para apropiársela y desplazarla. Estos elementos distorsionan el origen de la música, para ser montada en un epicentro nuevo y definitivo. Es así como, con su festival, Valledupar comenzó a ser el nuevo dueño del género musical. Como plantea Martín Barbero, (I998: 279): “...la apropiación y reelaboración musical se liga o responde a movimientos de constitución de nuevas identidades sociales". En torno al vallenato se da identidad cultural y un elemento cohesionador a toda la cultura del Valle de Upar, constriñendo y parcializando sus orígenes, haciéndole creer al país y a sus propios habitantes que son los dueños y creadores del vallenato.

Una prueba clara de este movimiento estratégico de apropiación es el hecho que Valledupar le haya dado su propio gentilicio como nombre a esta música. La llamaron vallenato es decir nato del valle-de Upar-, cuando es evidente que ésta es nata de 


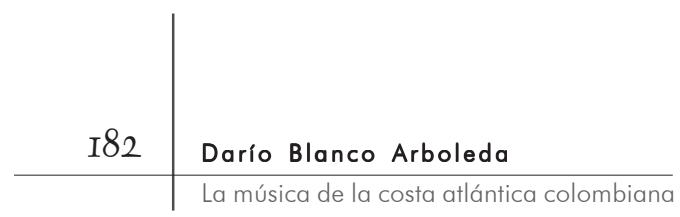

toda la costa atlántica. Otras regiones de la costa se rehúsan a usar este nombre y la llaman música de acordeón, como manera de protestar en contra de la apropiación y hegemoneización del folclor por parte de las elites de Valledupar.

Una de las personas más importantes dentro del proceso de desarraigo zonal de este folclor, para su restablecimiento posterior en Valledupar y reinvención de la historia del mismo, que le da un carácter mítico, fue Gabriel García Márquez y su novela Cien años de soledad, que se ha convertido en el paradigma de la cultura colombiana y gracias a la cual se le da una nueva historia a la música de acordeón. Es importante resaltar cómo el primer gobernador del Cesar hacía énfasis en la pertenencia de García Márquez a Valledupar, donde el Nobel logró su inspiración, de donde toma las historias y las recrea en su particular estilo literario. López Michelsen (I999: 2) plantea que en Escalona y en ninguna otra persona debe buscarse la fuente de donde bebe García Márquez para crear su más importante obra, precisamente en Escalona, pieza fundamental en la creación del festival de la leyenda vallenata.

Conjugados estos tres grandes personajes, el Cesar se consolida políticamente como departamento, se adopta un cohesionador cultural como lo es la música y a este montaje político-musical se le da un fundamento donde asentarse y echar raíces, por medio de la literatura garciamarquiana, en la que alcanza un hálito mítico ancestral, inexistente hasta entonces. Sólo tres décadas después de la época de éxito musical de Rafael Escalona, de la creación del festival de López Michelsen y de Cien años de soledad -nótese la coincidencia de las fechas-, el país entero cree que la música de acordeón es de Valledupar, que el Cesar es una región culturalmente distinta al resto del país y que todo esto viene de una historia remota.

Ahora bien, el éxito rotundo de la creación de estos tres hombres en particular, y de la elite valduparense en general, no llegó sólo hasta darle fuerza y cohesión cultural a una región como el Cesar. Actualmente, la música de Colombia es el vallenato. Es la que más se oye, la que más se vende, la que tiene más difusión comercial y de medios audiovisuales: “...pero el punto es que la música vallenata -de origen regional particular-es aceptada un representante legítimo del sentimiento nacional" (Wade, I997: $24,25)$. Finalmente, lo que ellos lograron fue "estabilizar una expresión musical de base popular como forma de conquistar 


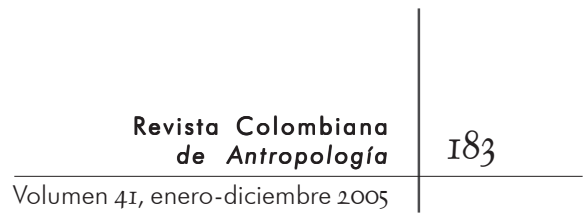

un lenguaje que concilie el país en la horizontalidad del territorio y en la verticalidad de las clases sociales" (Barbero, I998: 234). Esta labor es admirable y de esfuerzos colosales, si se tiene en cuenta la división cultural y política que mostraba Colombia antes de estos hechos: "Colombia podía llamarse antes de 1940 más un país de países que una nación” (Barbero, I998: 225).

Es innegable la audacia y la inteligencia demostrada por los artífices de esta novela-política-cantada, que en sólo treinta años se convirtió en una verdad irrefutable para toda Colombia. El festival de la leyenda vallenata, en sí mismo, funge como un gran evento ritual en el que se valida y renueva periódicamente esta construcción y hegemonía cultural y simbólica.

\section{Música y pOLítica}

2 s S IMPORTANTE RESALTAR TAMBIÉN QUE DENTRO DEL PROCESO DE NAcionalización -principalmente de aceptación del vallenato en el interior del país y el desplazamiento posterior del bambuco como la música colombiana- tiene gran influencia y relación la pugna por el poder político de los dos partidos más importantes, y los únicos que han regido la nación desde la independencia de España. Por una parte encontramos al vallenato asociado al Partido Liberal colombiano, partido con el que llegó al poder Alfonso López Michelsen (1974-I978) -su fortín electoral estaba en las zonas de provincia, principalmente en la costa atlánticaque por la época de expansión vallenata al interior adquiría mayor poder y representatividad. Por otra, vemos que, al mismo tiempo, el Partido Conservador se veía desplazado de esa posición privilegiada, en la que llevaba, hasta ese momento, una hegemonía histórica. No es coincidencia que la mayoría de los electores y la zona de más influencia de este partido fuera el interior del país, la llamada zona andina, que tradicionalmente ha sido representada por el bambuco, música llamada simplemente música colombiana.

Como puede observarse, el desplazamiento de un tipo de música por otro en el rubro de música de Colombia se encuentra relacionado por completo con la pugna de los partidos políticos por la hegemonía del país. Cuando estos dos géneros musicales se enfrentan por la representatividad total de la geografía nacional no lo 


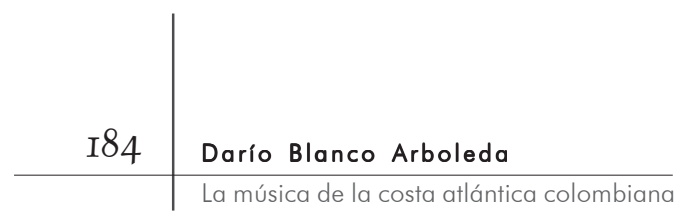

están haciendo, simplemente, dos tipos de música: el acento del desencuentro está en otro lugar muy lejano a los instrumentos, ritmos y melodías. El enfrentamiento real se da entre dos ideologías, entre diferentes maneras de concebir la vida, la religión, la sexualidad, el espacio público y privado, las estéticas. El conflicto es entre diferentes concepciones y apropiaciones de lo social y lo cultural, que en este caso se ven representados de manera simplificada por los partidos políticos. Al revisar, en general, la cultura representada por el vallenato estaba conformada por los grupos sociales que en lo político se veían aglutinados por el liberalismo. De forma similar, el bambuco representó, durante casi dos siglos (Miñana, I997: 8) a los grupos sociales del interior, que eran el caudal electoral del Partido Conservador. Mientras la elite del interior -líderes de ese partido- mantuvo su hegemonía sobre el resto del país, ésta mantuvo su propia estética musical idealizada, el bambuco, como representativa de la nación. Hacia la segunda mitad del siglo veinte, el liberalismo tomó fuerza y logró romper la hegemonía conservadora: en ese momento, el vallenato logró entrar a la región andina y, poco a poco, desplazó al bambuco de la posición de legítimo representante del sentir nacional.

\section{LA Música COlOMbiana en MONTERrey, N. L.}

En mi opinión, creo que es una música que llegó para quedarse totalmente, es un ritmo de vida que cada quien, por ejemplo mi forma de vivir yo siento que aparte de la Biblia y la educación de mis padres a mí me hizo el vallenato (Rodríguez, 2002).

Porque no sé si has escuchado los programas de radio, ahorita ya con tres programas de radio que pasan veinticuatro horas música colombiana, un programa de televisión que pasa videos, cada quince días vienen grupos colombianos. La última generación, los niños que ahorita tienen, que acaban de nacer o que tienen cuatro-cinco años, ya saben que pa' tocar vallenato tienen que comprarse un Corona III, ya saben que el vallenato se toca con los dos teclados al mismo tiempo, ya saben que se toca con caja, guacharaca y acordeón. O sea, que tienen información que yo no tuve cuando empecé a escuchar música colombiana. Esos chavitos dentro de diez años van a ser lo que dijo Consuelo (Araújo Noguera), que en paz descanse, cuando vino aquí, en ninguna parte del mundo está pasando lo que pasa aquí en Monterrey ni siquiera en Colombia (López, 2002). 


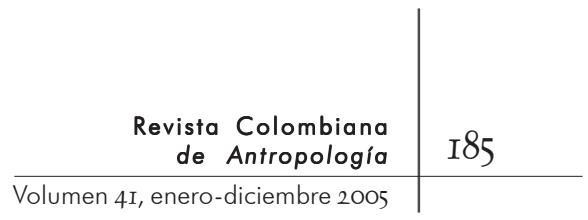

Porque ellos tocan el vallenato y si lo tocan es porque les gusta, desde ahí que es la diferencia con el ska y el rock, porque la mayor parte aquí, la mayor parte de las colonias hay grupos musicales y curioso es que cuando nacen hijos les ponen Israel, Rafael, Diomedes. Mi hijo menor se llama Calixto Diomedes, ¿cómo ves?, di si no llevamos esa música adentro. Aquí ser colombiano no significa haber nacido en Colombia sino una manera de vivir, una manera de apreciar una música, más que diferencias hay que hablar de coincidencias y si tú visitaras a las bandas en sus barrios es como si de repente entraras no sé como a una especie de parque temático, a un museo al aire libre donde estás viendo cantidad de cosas y sobre todo estás conociendo un mundo donde los jóvenes tienen corazones con forma de acordeón (Encinas, 2002).

\section{El arribo a la nueva geografía-cultural}

I A MÚSICA DE LA COSTA ATLÁNTICA COLOMBIANA, PRIMERO EL PORRO 4 pero sobre todo la cumbia, llegó a México hace unos cincuenta años (Pérez, 1995: 3), adaptándose y siendo acogida rápidamente en este nuevo territorio. Mediante procesos como el de reificación, adaptación y creación fue transformada, en primera instancia, en las cumbias tropicales, en el centro y costas del país, y después en la llamada cumbia norteña, en la región homónima. De igual manera, en la actualidad, la música del norte de México y sureste de Estados Unidos como la tejana, tex-mex, y parte de la llamada onda grupera poseen bases en la cumbia.

La cumbia, el porro, el vallenato y otros ritmos de la costa atlántica llegaron hacia la mitad del siglo veinte por medio de discos y de músicos que hacían giras en México. Fueron escuchadas con relativo éxito durante un tiempo y desaparecieron luego, a excepción de la cumbia, que sí tuvo arraigo en la mayoría del país. La cumbia se estableció definitivamente en México hacia finales de los años I960, interpretada por orquestas como la de Mike Laure y Rigo Tovar. Ellos, en su repertorio, muy exitoso y consumido, utilizaban la música de origen colombiano pero transformándola: las orquestas tropicales mexicanas mimetizaban el ritmo caribeño colombiano y lo transformaban en lo que ellos, o la industria discográfica mexicana, creían que era un sonido más adecuado para el público de estas latitudes, aun cuando sin dar crédito a sus compositores originales, de manera tal que el público creía que eran composiciones originales. 


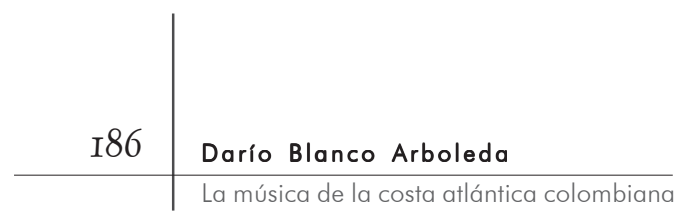

El vallenato, contrariamente a la cumbia, sólo logró establecerse en el norte del país, en Monterrey y algunas zonas cercanas; esta zona es la tierra del acordeón en México. Esto, sumado a la empatía que generan las letras de las canciones vallenatas, explica parcialmente su adopción en estas latitudes. El fenómeno de la música colombiana ${ }^{7}$ de Monterrey se desarrolla prácticamente en contra de los medios de comunicación masiva -que lo ignoraron de manera sistemática- y de los canales de comercialización de las disqueras, ya que sólo hasta fechas recientes ésta se ha difundido y comercializado. Parte de la explicación del arraigo de la música la encontramos en una gira de Los corraleros del Majagual, agrupación de la costa caribe colombiana que estuvo varada por bastante tiempo en esta zona, de frontera con Estados Unidos, por problemas de documentación. Esta estancia prolongada del grupo influyó en la percepción y el gusto musical en la región. Hasta la actualidad, los discos de ese grupo son consumidos ávidamente, y los protagonistas de este fenómeno concuerdan en señalar a Alfredo Gutiérrez -líder de la agrupación- como la piedra angular en el inicio del gusto por la música colombiana en esta latitud.

\section{El mantenimiento del fenómeno y la creación del gusto colombiano}

OSTERIORMENTE, LOS PERSONAJES CENTRALES EN LA ADOPCIÓN Y PER1 manencia de este fenómeno fueron los sonideros ${ }^{8}$, quienes durante décadas se encargaron de viajar a la Ciudad de México,

7. Utilizo los términos colombiano y colombia, en cursivas, para referirme al producto musical y al fenómeno híbrido propio de Monterrey.

8. Los sonideros alquilan su música, el equipo de sonido y la amplificación. Son contratados para amenizar fiestas de barrio, como las de quince años y los matrimonios.

9. Las ciudades puerto de esta zona fueron la vanguardia del movimiento modernizador colombiano y, en consecuencia, las primeras disqueras del país aparecieron precisamente allí. Estados Unidos y Colombia tras grabaciones de grupos colombianos de la costa atlántica. Ellos tenían un gran mercado debido a la escasez y altos costos de los grupos tropicales en aquellos años. Poco a poco, los archivos musicales de estos personajes singulares se fueron especializando en las versiones tropicales colombianas, provenientes todas de la costa atlántica ${ }^{9}$. 


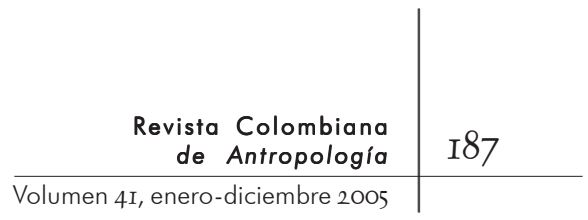

Esta colección ha crecido con los años y paralelamente se ha desarrollado una cultura musical colombiana dentro de Monterrey, de bases profundas y relativamente firmes. Los sonideros eran los únicos capaces de conseguir y pagar los discos colombianos que eran simbólicamente muy apreciados -por tanto escasos y costosos-. Así se mantuvo el consumo restringido hasta la aparición del casete en la década de I980 -tecnología que permitió la duplicación de la música-. Al ver disminuido su trabajo, se abocaron a grabar su acervo en este medio y a venderlo al público en general, ávido de esta música que no se conseguía en el mercado formal. En la actualidad, aun cuando ya se establecieron importadores legales, y las propias disqueras colombianas, el consumo sigue siendo predominantemente $p i$ -

II. Las rebajadas consisten en grabar las canciones con menos revoluciones. De esta manera, la música se escucha más lenta -como si a una grabadora se le estuvieran acabando las pilas-. Esta variación regia a la música colombiana tiene gran aceptación entre los seguidores del género, ya que sostienen que así se disfruta más la música, entienden con más facilidad la letra y se amainan los rápidos ritmos costeños. rata, debido a los altos costos de los discos originales y al arraigo de una cultura de consumo informal, dirigida por los sonideros, con mezclas especiales, compilaciones e hibridaciones, como los discos rebajados ${ }^{10}$ de amplio consumo entre los colombianos.

\section{La apropiación musical y la creación de un fenómeno sincrético}

I A PRODUCCIÓN DE MÚSICA COLOMBIANA EN MONTERREY SE ENCUEN$\downarrow$ tra liderada, principalmente, por Celso Piña, La tropa vallenata y La tropa colombiana. Celso Piña, pionero en estas lides, fue el primero en tocar con su grupo esta música -antes sólo se escuchaban los discos-y se ha caracterizado por "emular cuanto pueda el estilo colombiano". Esta característica lo había confinado a mantenerse en un bajo perfil, de restringida circulación, viendo cómo grupos posteriores a él, como Los vallenatos de la cumbia, lograban entrar en los circuitos internacionales de producción y distribución de la música, llegando principalmente al Cono Sur y a Estados Unidos (Olvera, 2002: 8). Su disco Barrio bravo lo catapultó al mercado internacional y le dio su merecido lugar dentro de la escena musical. Esta producción, que conmemora su vigésimo 


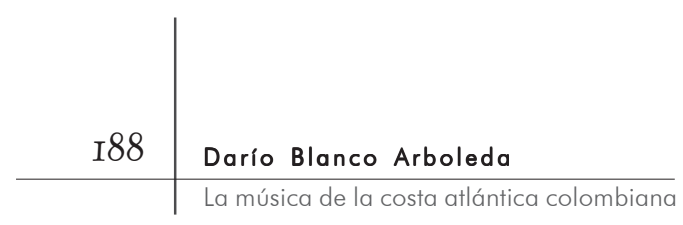

aniversario de carrera artística, intenta introducir a Piña al mercado de las músicas globales. Se busca un sonido más global, que pueda ser consumido en múltiples latitudes, por diferentes grupos sociales y generacionales. Debido a esto, las raíces étnicas y populares de la música se esconden, mezclándola con diferentes ritmos de mayor aceptación y de más fácil comercialización. Es claro que su gran éxito se debió a que dejó de lado, por primera vez, su tradicionalismo colombiano, haciendo mezclas con otros géneros y con artistas de gran aceptación entre los jóvenes de clase media y alta de todo México, logrando mimetizar el sonido y darle una nueva imagen. Con este disco, Piña logró la nominación al Grammy y se convirtió, de la noche a la mañana, en una estrella musical de orden internacional, cuando antes de Barrio bravo apenas era escuchado por grupos populares de Monterrey.

A finales de la década de 1980, el fenómeno colombiano hizo su aparición en múltiples grupos de adolescentes de sectores populares, que se organizaron en grupos juveniles, autodenominados de colombianos que, de igual manera, llaman colombia a su elección musical, transformando así el gentilicio en sustantivo. Estos grupos de colombianos han formado y son seguidores de agrupaciones locales mexicanas que producen un vallenato mexicano renovado, como La tropa vallenata, La ronda Bogotá, Los vallenatos de la cumbia, Grupo M-I9 colombiano, entre muchas otras.

Los consumidores y productores de la colombiana pertenecían sobre todo a los grupos populares y marginales de la ciudad -desempleados y, en el mejor de los casos, en la más baja escala de la actividad productiva-, por lo que otros grupos sociales los identifican, junto con su música, como pandilleros, drogadictos y, en general, delincuentes. El epicentro del gusto por esta música se encuentra en la Loma Larga, un cerro cercano al centro de Monterrey, que abarca alrededor de veinte barrios y principalmente a la colonia Independencia, de donde surgen los sonideros. A lo largo de la historia esta zona ha recibido migrantes del interior de la república, que poseen una cultura campesina y encuentran en la música colombiana muchos elementos comunes a ellos.

El surgimiento de estos primeros músicos colombianos coincidió con la aparición de una nueva propuesta identitaria, 'el ser colombia’. Se puede ver cómo la primera generación de grupos juveniles dejó de lado al rock -la propuesta identitaria juvenil por antonomasia-y adoptó a estos grupos como sus ídolos (Cruz, 


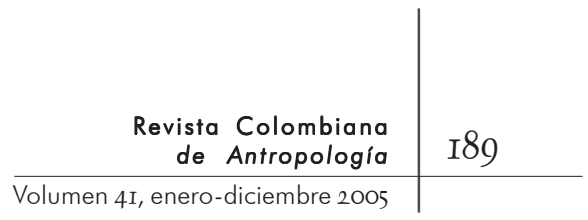

I996). Junto a los grupos profesionales existen otros que tocan por el simple gusto de reunirse y producir música; estos amenizan cantinas, bailes y celebraciones menores. Tocan también en los camiones de transporte público de la ciudad, recogiendo algo de dinero o, simplemente, hacen música en las esquinas.

Las razones dadas para la validación del consumo de este género en Monterrey van desde la gran variedad musical y de temáticas que ofrece, la invitación al baile que hacen sus ritmos, la facilidad de su ejecución y en la consecución de sus instrumentos -algunos, como el acordeón, se encuentran muy arraigados y los otros pueden fabricarse artesanalmente a bajo costo-, hasta la fuerza simbólica de sus letras, ya que cuentan historias principalmente campiranas que remiten a un pasado rural, de simpleza romántica muy apreciada por los colombias de Monterrey. El vallenato tiene una fuerte similitud estructural con el corrido mexicano, dada la preeminencia de la oralidad y de la función de contar historias, historias que permiten la construcción de subjetividades, que dan una carta de navegación a las personas para entenderse, reconocerse y actuar. Esta correlación corrido-vallenato no debe perderse de vista al intentar entender el por qué de la elección de la música colombiana en estas latitudes.

Es importante recordar que dentro del vallenato en Colombia existen varias vertientes, algunas más populares, otras de mayor aceptación por las clases medias y altas -como el de Carlos Vives-. El tipo de vallenato que llega y se arraiga en Monterrey es el popular, aquel con mayor apego al estilo tradicional, menor estilización y temáticas campiranas más cercanas a sus propias vivencias, lo que lo hace fácilmente traducible a sus propios parámetros culturales.

\section{La entrada del mercado y el establecimiento del contacto transnacional}

D ESPUÉS DE TREINTA AÑOS, LOS CIRCUITOS COMERCIALES DE LA MÚSICA en Monterrey tuvieron que reconocer el gran mercado que venían desaprovechando con este género. De esta manera, en la actualidad en cualquier tienda de música se pueden encontrar discos nacionales e importados de cumbia y vallenato, aun cuando más costosos que los de cualquier otro género. 


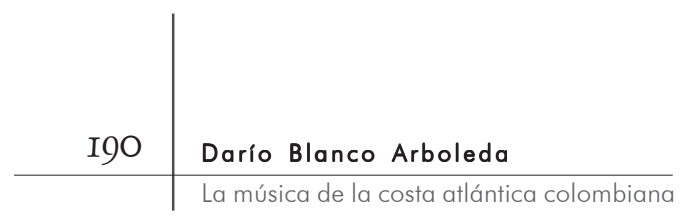

Los medios de comunicación masiva de Monterrey han visto con desprecio el fenómeno regio-colombiano, ignorándolo sistemáticamente, y aun cuando el mismo tiene gran audiencia han hecho una labor de invisibilización, como si al ignorarlo y bloquearlo pudieran desaparecerlo -al menos mediáticamente-, dejándolo sin voz ni instrumentos de difusión. Las únicas excepciones a esta generalidad se encuentran en la caricaturización y la mofa, que buscan minar y erosionar su poder simbólico como elección identitaria válida y contestataria.

A partir del reconocimiento del grave descuido-consecuencia del descubrimiento del amplio potencial comercial de esta parcela del mercado- se inició una nueva etapa en la que se brindan ampliamente los productos que consume este sector, olvidado por décadas. En los últimos años se han creado tres estaciones radiales exclusivas del género, y en muchas emisoras más se comienza a programar por segmentos. En el mercado formal y en el informal es posible encontrar una amplia comercialización de todos los productos relacionados con la misma, desde discos hasta videos, camisetas, sombreros de vueltas o instrumentos. Se traen músicos de Colombia para realizar conciertos, en sitios de alto estatus y costos elevados, donde los sectores sociales privilegiados pueden aparecer sin incomodidades y sin necesidad de mezclarse con los demás grupos sociales.

Desde la segunda mitad de los años I990 apareció en Monterrey la primera estación radial comercial con programación netamente colombiana: la XEH. Al percatarse del tremendo éxito de la misma surgieron, en 1999, dos estaciones radiales nuevas con las mismas características: Radio I3 y La Guacharaca -esta última renombrada recientemente el Bombazo vallenato-.

El fenómeno regio-colombiano se ha extendido hacia Saltillo, Laredo, Monclova, León y San Luis Potosí, y en general a la zona norte de México, ampliando su masa receptora. En estos sitios se vive la misma situación y se escuchan los mismos músicos que en Monterrey quince años atrás.

En Monterrey está en su apogeo un debate el que se encuentran dos bandos: por un lado, los defensores del producto musical transformado, amalgamado, adaptado a la realidad sociocultural de la región, la colombiana, consumida principalmente por los grupos populares y los grupos juveniles-colombias-. Por otro, un grupo de elite que promueve la entrada de 


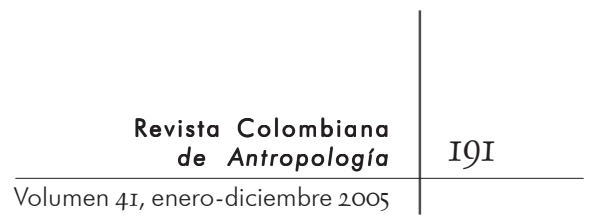

esta música en nuevos grupos sociales para que sea escuchada por todo Monterrey. Este grupo está compuesto por profesionales, empresarios, músicos, locutores radiales, trabajadores sociales-culturales y algunos colombianos radicados en la ciudad. Ellos han tenido la oportunidad de adquirir un amplio conocimiento del género vallenato vía internet, libros, videos, discos $\mathrm{y}$, principalmente, mediante viajes al festival de la leyenda vallenata en Valledupar. De esta manera han organizado dos versiones propias del festival vallenato en Monterrey, con el apoyo de las directivas del festival de Valledupar, que ha enviado en varias oportunidades a los reyes vallenatos colombianos a hacer presentaciones y conciertos.

De 1960 a 2000 muy pocas personas de Monterrey habían viajado al festival, pero en épocas recientes, cada año el número aumenta, ya que para estos colombianos ir a Valledupar es como llegar a la tierra prometida y en no pocos casos venden sus pocas pertenencias o se endeudan para cumplir con este sueño. En consecuencia, en 2005 se organizó formalmente una excursión para ir al festival de la leyenda vallenata y viajó un gran número de aficionados. Así mismo han enviado en dos ocasiones un grupo vallenato regio a concursar a Valledupar, en la categoría de mejor acordeonero, han concursado muchas veces en canción inédita y se han hecho planes y arreglos con las directivas del festival de la leyenda vallenata para asegurar la participación en los festivales venideros y para seguir organizando festivales y presentaciones musicales en Monterrey.

Desde 2000 hasta 2005 encontramos que la música colombiana se ha expandido dentro de todos los grupos sociales de Monterrey. En la actualidad, la música vallenata ha alcanzado los grupos sociales medios y altos, y se escucha en los bares y discotecas más exclusivos de la ciudad, algo inimaginable hace pocos años. El estigma que tenía esta música desaparece lentamente, de la misma forma que desapareció de Colombia en la década de 1990. Todo parece indicar que en unos años la música vallenata podría ser la más escuchada y la más exitosa con el apoyo total de los medios de comunicación masiva. 


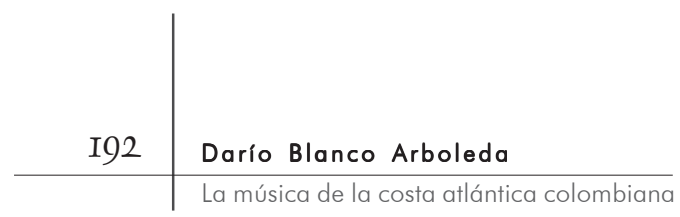

\section{LA MÚSICA CARIBEÑA COLOMBIANA COMO UN FENÓMENO TRANSCULTURAL}

\begin{abstract}
C
II. Se utiliza el término en inglés, proveniente del fenómeno urbano estadounidense de posguerra (Pop culture), ya que el término en español (cultura popular) posee otras connotaciones muy diferentes y en Latinoamérica, incluso, algunas características premodernas.

I2. Para profundizar sobre este asunto, véase Feld, 200I.
\end{abstract}

OMO OTROS PRODUCTOS CULTURALES, EN LA ACTUALIDAD LA MÚSICA SE ve expuesta a desplazamientos vertiginosos entre los ámbitos local y transnacional, catalizada por la modernidad y la globalización. Las corrientes principales dentro de estos estudios, como la etnomusicología, los trabajos sobre las músicas del mundo (world music) o de música pop $^{11}$ hablan de expresiones musicales que, en general, implican una asimetría entre el origen y las zonas adonde se desplazan. La música de la costa atlántica colombiana muestra una transnacionalización, pero desde lo popular, entre grupos sociales de escasos recursos. Se diferencia de la world music o la etnomusicología, ya que éstas son generadas en contextos tribales, étnicos, del Sur, es decir, de la Otredad. El material recolectado como objeto de museo debe ser curado para ser exhibido, además de transformado, mimetizado y eugenizado, con el fin de ser consumido en el Norte, en un ejercicio simbólico de etnología de rescate. Ejemplos de esto los encontramos en la música tribal, étnica, distribuida por todo el mundo mediante la categoría -aglutinadora de una inmensa diversidad, hoy en día eminentemente comercial- world music ${ }^{12}$. Estas características se hallan igualmente en géneros como el reggae, el ska, la salsa, el son, el tango, etcétera. La música colombiana se diferencia también del otro fenómeno ampliamente estudiado por los académicos, la música pop, ya que estos son géneros musicales creados y desarrollados en el mundo hegemónico y que, desde ese centro, apoyados por la industria musical, se distribuyen hacia las periferias. Otros ejemplos de este fenómeno los encontraríamos en el rock, el punk, el metal, el rap, el hip-hop, entre otros.

En este sentido, la música caribeña colombiana puede verse como un fenómeno de intercambio cultural-simbólico Sur-Sur. Vemos cómo una música del Sur llega al Sur, y se establece, por lo menos en un caso, sin mayor ayuda de la poderosa industria musical y de todos los agregados a ésta en el ejercicio de la comercialización y el consumo. Externamente a la industria 


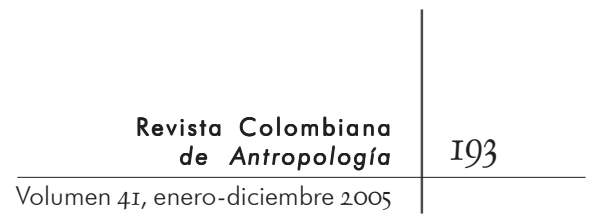

comercial musical logra el mantenimiento de un género por medio de circuitos subterráneos durante años. Luego, por intermedio de estos circuitos, logra expandirse hacia Estados Unidos pero se mantiene dentro de los grupos migrantes provenientes del Sur, mostrando cómo, hasta fechas recientes, esta música ha sido escuchada y bailada por las clases populares latinoamericanas, incluso recientemente en el Cono Sur con la cumbia villera ${ }^{13}$-al igual que en Monterrey- entre grupos de jóvenes marginales.

Dentro de este campo disciplinario los casos trabajados se refieren principalmente a desplazamientos Norte-Sur o viceversa, por lo general en condiciones severas de desigualdad, presente, como en todos los campos, también en la cultura y sus bienes como la música. La música de la costa atlántica colombiana brinda la oportunidad de comprender las dinámicas y lógica de un desplazamiento SurSur, entre clases sociales de base, en la producción, recepción, consumo y adaptación musical.

La música caribeña colombiana es un caso atípico dentro del estado del arte sobre la transnacionalización de los productos culturales, y puede brindar valiosos aportes a la teoría general sobre globalización,

13. La cumbia villera proviene de las villas miseria ubicadas en las periferias de Buenos Aires. Es importante resaltar la similitud de las cumbias colombianas de Monterrey con las villeras. Esta música llegó y se estableció desde hace muchos años en las zonas marginales de la Argentina, y en tiempos recientes la gente de las villas estableció, por medio de esta música, un nuevo tipo de oposición a sistema neoliberal y a las condiciones de pobreza que sufre. Al mismo tiempo, esta versión sincrética de la cumbia se ha constituido en el elemento identitario primario para estos grupos populares. En las letras de las villeras se encuentran apologías a los Pibes Chorros, adolescentes que roban en los barrios ricos y llevan sus ganancias a las villas -al mejor estilo de Robin Hood-. Al mismo tiempo, en las letras de las cumbias villeras se oyen referencias continuas a drogas, sexo y violencia, y por este medio sus compositores, intérpretes y oyentes han encontrado una poderosa herramienta de protesta social y política. Así, en las letras se establecen continuas ironías y burlas en contra de la policía, el gobierno y el estado argentino, hasta el punto de que el gobierno decidió prohibirlas, generando tal descontento que se vio obligado a dar marcha atrás y pedir disculpas. transnacionalización y transculturalidad, alejándonos y brindándonos elementos para contrapesar la posición neocolonialista con que se ha manejado este campo y su teoría.

En la actualidad, dicha música se ve expuesta a un proceso de rearticulación que genera múltiples interlocuciones y tensiones entre la producida por sus primeros cultores, la que pide, produce y moldea el mercado global, y la que hacen los grupos sociales que la adaptan a nuevas geografías adonde llega gracias 


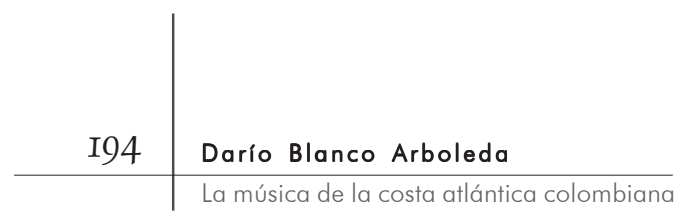

al mercado global y las migraciones. En este proceso de expansión del género se establece un diálogo, al mismo tiempo que se miden fuerzas. Esto hace que los parámetros se transformen aquí y allá, dependiendo de las tensiones y la aceptación de un público cada vez más amplio, lo que genera pugnas, reapropiaciones y acuerdos. Este es un proceso de transferencia y desplazamiento que va desde lo local hasta lo transnacional, pasando por referencias regionales y nacionales, para, una vez superadas, realizar una rearticulación que vuelve al ejercicio identificatorio en el ámbito local. Dentro de la música costeña colombiana -entre otras músicas transnacionales- es posible imaginar este desplazamiento como un periplo en el que el constructo cultural parte de su localidad natal para irse expandiendo hasta traspasar las fronteras. Una vez fuera de ellas se establece de manera ubicua en diversos países, pero no en todo su territorio, sino en localidades pequeñas, semejantes a las de donde partió, donde sufre un proceso de resignificación y de reterritorialización. Parafraseando a Ramón Pelinski, quien trabaja el tango nómade, el vallenato y la cumbia al salir de Colombia y migrar hacia nuevas ciudades se convierten en interculturales. En el transcurso de su desterritorialización se ven obligados a seleccionar rasgos estilísticos, a transformarse al interactuar con las estéticas musicales sobre las que se reterritorializan, haciéndose inteligibles para éstas. El vallenato y la cumbia logran mutaciones musicales en la cultura receptora, además de simbolizar este proceso de transformación sociocultural, dando como resultado una expresión musical mestiza (2000: 33), sincretizada y con capacidad identificatoria. Al ser resignificados son traducidos, además de amalgamarse con la tradición musical y cultural existente.

Se trata de un diálogo continuo entre lo global y lo local, encontrándose numerosas mediaciones en el interludio. Este fenómeno se ha expandido fuera de su territorio, pero debe compartir este nuevo espacio de significación con otras expresiones culturales globalizadas, sumadas a las expresiones culturales del lugar de recepción, dando como resultado un nuevo producto cultural denominado por sus intérpretes y público como la colombiana.

Es importante saber que entre numerosas elecciones musicales posibles, en una zona de gran riqueza y fuerza musical -cuna de la música regional e industria relacionada más vigorosa de México- se escoge e implementa un producto trans-fronterizo que se encontraba, parcialmente, por fuera de los circuitos 


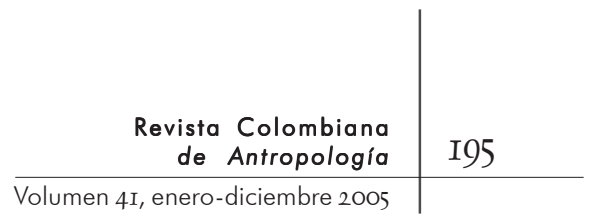

comerciales, de los medios de comunicación masiva, perteneciente a un país lejano, desconocido, y que poco a poco se va erigiendo en un imaginario predominante y un referente simbólico poderoso que sirve de referente, que determina y representa su subjetividad, se convierte en una poderosa herramienta identitaria.

\section{Conclusiones}

A MÚSICA DE LA COSTA ATLÁNTICA COLOMBIANA, ESPECÍFICAMENTE EL vallenato y la cumbia, ha hecho un largo periplo, otorgando identidad a los grupos más diversos. Desde un origen local particular, pasando a ser música regional, luego nacional y terminar siendo exportada a múltiples regiones del planeta. Particularmente en México, en la ciudad de Monterrey, encuentra un nicho fértil para su adopción y desarrollo posterior, cerrando de esta manera el círculo, ya que sale del ámbito local para terminar de la misma manera e iniciar un nuevo ciclo.

Esta música fue desarrollada originalmente por grupos de ascendencia afro, campesinos, iletrados, parte del fondo de la escala social de la costa atlántica colombiana. La música costeña comienza, poco a poco, a ampliar su masa receptora hasta llegar a convertirse en la de las clases populares en su región de origen. Posteriormente, liderada por músicos blancos y orquestas bajo la influencia estadounidense de grand band, tiene su primera transformación radical, que le permite romper la resistencia de las clases sociales dominantes en su región, convirtiéndose en la música que le otorga identidad a toda esta región. El vallenato en Colombia continuó siendo una música nacional, pero de clases populares, hasta la llegada de su segunda gran transformación, liderada por otro músico blanco bajo la influencia rockera, quien realiza fusiones con ritmos menos estigmatizados y, por ende, de mayor comercialización.

Hacia mediados del siglo veinte, cuando aparece la música de la costa atlántica en México, encontramos que primero llegó la cumbia y luego el vallenato a la capital de la república. La cumbia logró su adopción rápidamente, y desde el D. F. se expandió exponencialmente, siendo bailada por toda la geografía nacional, llegando incluso por el norte de México hasta el suroeste de Estados 


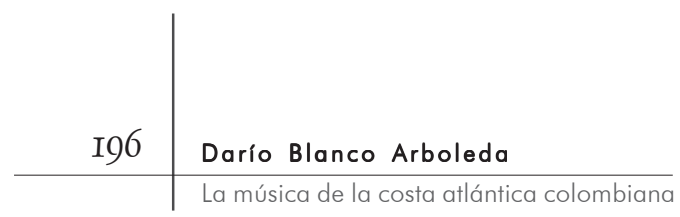

Unidos. El vallenato, por su parte, no tuvo el mismo éxito que la cumbia en todo México y sólo encontró amplia aceptación en la ciudad de Monterrey. Allí se creó un novedoso producto musical denominado regio-colombiano, que llega a dar identidad a los grupos sociales más bajos de la ciudad. En la actualidad, el regio-colombiano cumple esta función identitaria con numerosos grupos de chavos banda, que se encuentran en condiciones de marginalidad social, y se amplía hacia otros sectores sociales más favorecidos.

La música caribeña colombiana muestra dos procesos de transnacionalización, contradictorios y contrapuestos, aun cuando hablo de un fenómeno con el mismo origen. Por un lado se observa la música costeña transformada y eugenizada por la poderosa industria musical y el mercadeo, con el fin de otorgarle un perfil más comercial. Esta música se comercializa desde Estados Unidos (Miami), siendo redistribuida por las disqueras majors en ese país y Latinoamérica. En este caso es importante notar que la distribución se dirige, principalmente, a los grupos sociales medios y altos, en contraste con el caso de Monterrey, adonde llega la música más popular.

Se encuentra así una música eugenizada, transformada, bajo los parámetros comerciales y difundida globalmente por los medios de comunicación masiva. Esta es la música que pudo romper las fronteras regionales y sociales en Colombia, permitiendo a la nación entenderse por primera vez como un país unificado y haciendo literal el título de la música colombiana. Esta música se difunde sobre todo en Latinoamérica, Europa y Estados Unidos, pero para lograr esto debe perder muchas de sus características más autóctonas y originales, desdibujándose su esencia local. En este sentido, encontramos que lo local y lo global se mantienen en una interacción y retroalimentación continua. Lo local le brinda sangre y vida a lo global, y lo global le otorga a lo local difusión a espacios y geografías sin restricciones ni fronteras. Sin embargo, para lograr este nivel de difusión lo local debe perder parte de su esencia.

En la otra cara de la moneda encontramos en su origen una música local, campesina, con ascendencia afro, que habla en sus líricas de animales, de la naturaleza y del trabajo rural. Esta música, que en su país de origen se encontraba confinada y estigmatizada otorgándole identidad únicamente a sus cultores en 


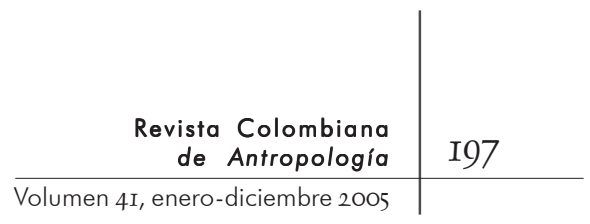

la costa atlántica, es tomada por las primeras compañías disqueras del país y logra difundirse por medio de las grabaciones y la radio por toda Latinoamérica. Se establece en las zonas más populares de las ciudades y es adoptada como propia; con los años se crean versiones nacionales híbridas. Una música local, que no puede superar las fronteras internas de su nación, logra dar identidad en Latinoamérica a sectores populares de las ciudades como es el caso de la colombiana de Monterrey, y la cumbia villera de la Argentina. Esta música le otorga un modelo de subjetividad a los grupos populares de las ciudades, en general migrantes internos, estigmatizados, y que encuentran en ella, además del manejo de su cuerpo mediante el baile, una herramienta poderosa de protesta social.

En el caso de los colombianos de Monterrey, es de resaltar que sólo tuvieron relación con los medios de comunicación masiva por conducto de las disqueras locales de Colombia, que no tenían comercialización efectiva fuera del país. Debido a esto es tan singular e importante el fenómeno colombiano de Monterrey, ya que lucharon por mantener su elección musical sin el apoyo de los medios y en contra de la sociedad regia que los estigmatizaba. Ellos construyeron sus propios canales subterráneos de consecución, mantenimiento y creación de un gusto musical y durante más de treinta años mantuvieron vivo el fenómeno. Es un desplazamiento musical desde una periferia local del Sur a otra periferia local del Sur, distanciadas por miles de kilómetros, sin la intervención de la comercialización internacional y los medios de comunicación masiva.

\section{Bibliografía}

Anderson, Benedict. I993. Comunidades imaginadas. Reflexiones sobre el origen y la difusión del nacionalismo. Fondo de Cultura Económica. México.

Araújo Noguera, Consuelo. 1973. Vallenatología: orígenes y fundamentos de la música vallenata. Ediciones Tercer Mundo. Bogotá. Bogotá.

ARAúJO, SAMUEL. 2000. "Brazilian identities and musical performances". Diogenes. 48 (I9I). 


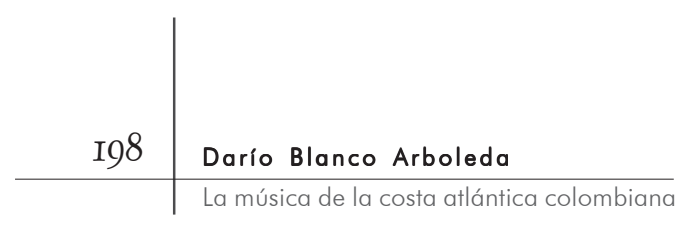

Atehortúa Gil, Carlos Alberto. I997. "La cosa fue así”. Revista del XXX Festival de la Leyenda Vallenata. Editora Guadalupe. Bogotá.

Ávila, Hugo. I993. "Vallenato para todos". Nueva Frontera. 959, noviembre.

Baquero Bracho, Hernán. i994. El vallenato en el tiempo y las voces de siempre. Editorial Antillas. Barranquilla.

Barbero, Jesús. I997. "De la telenovela al vallenato”. A Contratiempo. 9. Bogotá.

- I998. De los medios a las mediaciones. Convenio Andrés Bello. Bogotá.

- I985. Transnacionalización tecnológica y resistencia cultural. UAM. México.

Bejarano GonzÁlez, Bernardo. 2002. "Para los colombianos, los eventos culturales más importantes son de la Costa Caribe”. El Tiempo. Bogotá. Sección Cultura. II de julio.

Ben-amos, Dan y Goldstein Kenneth (eds.). i975. Folklor; performance and communications. Mouton. The Hague.

Berger, Peter y Luckman, Thomas. ig68. La construcción social de la realidad. Amorrortu. Buenos Aires.

Blanco, ARBOlEDA, DARío. 2004. "La música de la costa atlántica colombiana, hija adoptiva de Monterrey, Nuevo León”. Revista Culturas Populares. 5. Conarte, Dirección de Culturas Populares. Monterrey.

Bruges Carmona, Antonio. i940. "El merengue, danza típica del Magdalena”. El Tiempo. Bogotá. 2I de enero.

- I950. "Noticia de los últimos juglares”. El Tiempo. Bogotá. I9 de marzo.

Burnett, Robert. I996. The global jukebox. The international music industry. Routledge. Londres/Nueva York.

Cedillo, Juan Alberto. 2002. "El músico, que tiene 20 años tocando cumbias y vallenatos en su tierra natal, aún no conoce Colombia”. http://www.eluniversal.com/zona/2002/og/oI/musica2a.shtml

Cruz, Arturo. 200I. "Desde Monterrey...pura cumbia colombiana”. La Jornada. México, D. F. 26 de abril. La Jornada de Enmedio.

Cruz, Gregorio. I996. “Informales y semiprofesionales”. Olvera, Torres, Cruz y Jaime. La Colombia de Monterrey. Monterrey (reporte de investigación no publicado).

"El festival vallenato es una realidad nacional, Consuelo Araújo, La Cacica, principal artífice”. Revista Cesar 20 años. Publicado por la Gobernación del Cesar, mayo de I987. Barranquilla. 


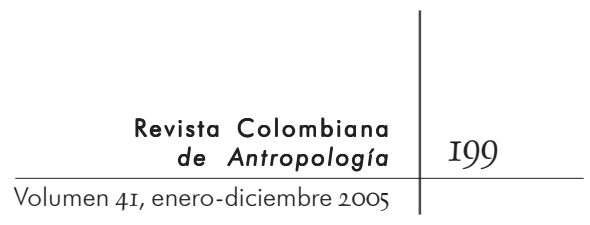

EL TIEMPO. 2002. "El imperialismo cultural costeño”. Bogotá. Editorial. I7 de julio.

EnCINAS, José LORENZO. 2002. Entrevista personal. Monterrey. Trillas. México.

- I998. "Triunfan colombianos en tierra norteña. El Binomio de Oro logra reunir poco más de 40 mil regiomontanos, que bailan, brincan y cantan los éxitos de este conjunto”. El Norte. Monterrey. Sección Metro. 26 de octubre.

. 1998. "Del Binomio pa' la raza”. El Norte. Monterrey. Sección Metro. 27 de octubre.

- 1999. "Invaden vallenatos tierra grupera. En la Expo Guadalupe se realizará el primer Festival mundial del vallenato". El Norte. Monterrey. Sección Metro. II de febrero.

- 2002. "Vallenato en Villaseca, asisten cerca de 2 mil 500 personas ente jóvenes y familias a la presentación de cinco agrupaciones vallenatas, en medio de las fiestas de Linares". El Norte. Monterrey. Sección Metro. 8 de agosto.

FinNegan, Ruth. 1998. "Por qué estudiar la música, reflexiones de una antropóloga desde el campo". Antropología. Revista de pensamiento y estudios etnográficos. 15-16. Marzo-octubre.

García Márquez, Gabriel. 1982. Textos costeños. Editorial Bruguera. Barcelona.

Bogotá. I9 de junio.

GIlARD, JACQUeS. 1993. “¿Crescencio o don Toba?”. Huellas. 37. Abril.

Gossain, JuAn. I993. “iAy hombre!”. Semana. 605. diciembre 7.

Grimson, Alejandro. 2000. "Interculturalidad y comunicación". Enciclopedia latinoamericana de sociología y comunicación. Editorial Norma. Buenos Aires.

GuERrero, Antonio. I999. "De los gruperos a los cholombianos". Jóvenes. Revista de estudios sobre juventud. 9. Cuarta época, año 3. Juliodiciembre. México.

Gutiérrez, Tomás Darío. 1992. Cultura vallenata, origen teoría y pruebas. Plaza y Janés. Bogotá.

Hall, Stuart. 1995. “The question of cultural identity”. En Hall Stuart, Held David, Hubert Don, Kenneth Thompson (eds.). Modernity an introduction to modern societies. Polity Press. Cambridge, U.K. 


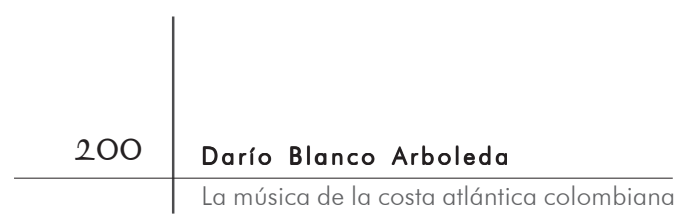

Hernández, PABlo. I998. "Nezahualpolvo, Una historia a través de la música”. Jóvenes. Revista de estudios sobre juventud. 6. Cuarta época, año 2. Enero-marzo. México.

JiMÉNEZ, ARTURO. 2003. "El vallenato, tema de pieza dramatúrgica; Alicia dorada (sic) en Monterrey, de Orlando Cajamarca”. La Jornada. México. Sección Cultura. 4 de enero.

Jiménez, Roque. 1992. Breve historia de la música popular Costeña. Editorial Antillas.

JóvenES. REVISTA DE ESTUdios SOBRE JÓVENES (sin autor). I996. "Los caminos de la vida”. Sección Música. Cuarta época, año I (I). Julioseptiembre. México.

Lara, María Eiletí́a. s. f. "La música popular en el norte de México en tiempos de globalización”. Departamento de historia-INAH-Sonora.

List, George. 1983. Music and poetry in a colombian village. A tricultural heritage. Indiana University Press. Bloomington.

Llerena Villalobos, Rito. s. f. Memoria cultural en el vallenato. Universidad de Antioquia. Medellín.

LeÓn Zaragoza, Gabriel. 200I. "Los acordeones de El Flaco y Celso cimbraron el Zócalo capitalino”. La Jornada. Sección Espectáculos. I8 de noviembre. México.

López Michelsen, Alfonso. I973. Carta prólogo a Vallenatología. Ediciones Tercer Mundo. Bogotá.

—_. 1997. "Cien años de vallenato". El Tiempo. Bogotá. I7 de agosto.

. 1997. "Entrevista a Viva FM de Caracol". Revista del XXX Festival de la Leyenda Vallenata. Editora Guadalupe. Bogotá.

- 1999. "Rescate de nuestra imagen". El Tiempo. Lecturas Dominicales. Bogotá. 24 de octubre.

López, Luis MANuel. 2002. Entrevista personal. Monterrey.

MAAlouf, Amin. I997. "Mi identidad, mis pertenencias". Identidades asesinas. Madrid. Alianza Editorial.

Martínez Polo, Liliana. I999. "La leyenda vallenata invade México". El Tiempo. Bogotá. I8 de julio.

. 2004. "La cumbia norteña en Colombia. ¿Un fenómeno a la fuerza?”. El Tiempo. Bogotá. Sección Cultura. 2 de marzo.

McClary, Susan. 1997. "Música y cultura de jóvenes. La misma historia de siempre". A Contratiempo. 9. Nueva época. Ministerio de Cultura. Bogotá. 


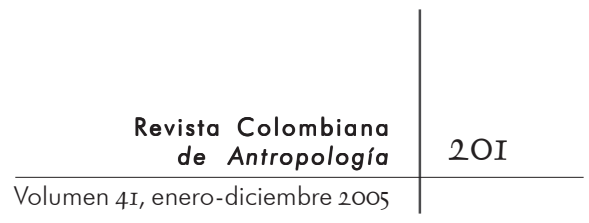

Mendoza Sierra, Luis. I999. "Quién, cómo y por qué inventaron el festival vallenato, la verdad verdadera”. Revista Expectativa.II9. Abril.

Miñana, Carlos. I997. "Los caminos del bambuco en el siglo XIX”. $A$ Contratiempo. 9. Bogotá.

Monsiváis, Carlos. 200I. "Vallenato y cumbia se nacionalizan mexicanos”. La Jornada. México. 26 de abril. La Jornada de Enmedio.

Moreno Rivas, Yolanda. [1979] I989. Historia de la música popular mexicana. Alianza Editores, CNCA. México.

Morin, Edgar. 2000. "Vaqueros y gruperos en el rodeo Santa Fe". Jóvenes. Revista de estudios sobre juventud. Nueva época. Abriljunio.

Ochoa, Ana María. I998. "El multiculturalismo en la globalización de las músicas regionales colombianas”. En Jesús Martín Barbero y Fabio López de la Roche (eds.). Cultura, medios y sociedad. CES/ Universidad Nacional. Bogotá.

I998. "El desplazamiento de los espacios de la autenticidad: una mirada desde la música”. Antropología. Revista de pensamiento y estudios etnográficos. I5-I6. Marzo-octubre.

Olvera, José Juan, Benito Torres, Gregorio Cruz, César Jaime RodríGuez. I996. "La Colombia de Monterrey. Descripción de algunos elementos de la cultura colombiana en la frontera norte”. Reporte de investigación no publicado. Monterrey.

Olvera, José JuAn. I998. “Colombianos en Monterrey. Génesis y prácticas de un gusto musical y su papel en la construcción de una identidad”. Tesis de maestría. Universidad Autónoma de Nuevo León, facultad de filosofía y letras, Monterrey.

. s. f. "Al norte del corazón. Evoluciones e hibridaciones musicales en el noreste mexicano y sureste de los Estados Unidos con sabor a cumbia”. Ponencia presentada en el III Congreso latinoamericano de la Asociación Internacional para el Estudio de la Música Popular”. http://www.hist.puc.cl/historia/iaspmla.html

. 2002. "Continuidad y cambio en la música colombiana en Monterrey”. Ponencia presentada en el IV Congreso latinoamericano de la Asociación Internacional para el Estudio de la Música Popular. México.

PANtoja, Jorge. 1998. "La música siempre mueve multitudes. En busca de pistas para la historia de la música popular". Jóvenes. Revista de estudios sobre juventud. 6. Cuarta época. México. Enero-marzo. 


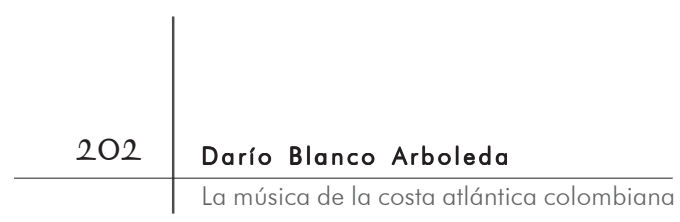

Pelinski, Ramón. 2000. “El tango nómade”. En Ramón Pelinski (comp.). El tango nómade. Ensayos sobre la diáspora del tango. Ediciones Corregidor. Buenos Aires.

Peña, Manuel. 1985. The Texas-Mexican conjunto: History of a workingclass music. University of Texas Press. Austin.

Perdomo Escobar, José Ignacio. I945. Historia de la música en Colombia. Biblioteca Popular de Cultura Colombiana. Bogotá.

Pérez, Alejandro (ed.). I995. Historia de la música popular mexicana. Los tropicales años 40. Segunda serie. Fascículo 4. Promexa. México.

Pulgarín, Carlos A. I998. "No soy mito ni leyenda, soy simplemente Escalona”. El Tiempo. Edición Caribe. 9 de julio.

Quintero Almenárez, Alba. 2000. "Valledupar y Monterrey unidas por el vallenato”. El Heraldo. Barranquilla. Sección Regional. 8 de enero.

Quiroz, Otero. I983. Vallenato hombre y canto. Icaro Editores.

Ribeiro, Gustavo. i996. Globalización y transnacionalización. Perspectivas antropológicas y latinoamericanas. Departamento de Antropología, Universidad de Brasilia. Brasilia.

Rodríguez, RomeO. 2002. Entrevista personal. Monterrey.

Samper Pizano, Daniel. I993. “iCon sentimiento!”. Cambio i6 Colombia. 25. Noviembre 29.

—. I997. "El vallenato coge ritmo". El Tiempo. Bogotá. 20 de abril.

. I998. "Rafael Escalona Martínez”. El Tiempo. Bogotá. Lecturas Dominicales. 2 de agosto.

Santos Calderón, EnriQue. I993. "El vallenato vive en Vives”. El Tiempo. Bogotá. 2 de septiembre.

—. I992. "Guayabo por Valledupar”. Semana. Bogotá. 26 de abril.

Stanford, Thomas. 2002. La música, puntos de vista de un etnomusicólogo. Fondo de Cultura Económica. México.

Sturman, Janet. 2003. “Technology and identity in Colombian popular music-techno-macondismo in Carlos Vives's approach to vallenato”. En R. T. Lysloff, L. C. Gay, J. R. Wesleyan (eds.). Music and Technoculture. University Press. Middletown.

Thompson, John. I990. Ideology and modern culture. Critical social theory in the era of mass communication. Polity Press. Cambridge, U.K. 
Vila, PABlo. 2000. "Música e identidad. La capacidad interpeladora y narrativa de los sonidos, las letras y las actuaciones musicales". En Piccini, Rosas, Schmilchuk (coords.). Recepción artística y consumo cultural. INBA/Ediciones Casa Juan Pablos. México.

VIVES, CARLOS. 1993. Entrevistado en: "Vives: la nueva leyenda vallenata". Credencial. 84. Noviembre. Bogotá.

WADE, Peter. 1997. "Entre la homogeneidad y la diversidad: la identidad nacional y la música costeña en Colombia”. En M. V. Uribe y E. Restrepo (eds.). Antropología en la modernidad: identidades, etnicidades y movimientos sociales en Colombia. Instituto Colombiano de Antropología. Bogotá.

Yudice, George. 1999. "La industria de la música en la integración de América Latina-Estados Unidos”. En Néstor Canclini García (coord.). Las industrias culturales en la integración Latinoamericana. Grijalbo. México.

ZAMARripa, Roberto. 200I. "Rey de vallenato en el D. F. Celso Piña hace bailar a los cientos de jóvenes roqueros que acuden a verlo la noche del miércoles en el salón 2I”. Reforma. México, D. F. 3I de agosto.

Zapata Olivella, Delia. 1962. "La cumbia, síntesis musical de la nación colombiana. Reseña histórica y coreográfica”. Revista Colombiana de Folclor. III (7). Segunda época.

Zapata Olivella, Manuel. I952. "Danzas y folklore”. El Tiempo. Bogotá, 26 de octubre.

. 1996. "Vallenato: folclore, psicología y romance". Romanceros. I. Diciembre.

Recibido: 25 de junio de 2003.

Aprobado: 18 de febrero de 2004. 